\title{
Los enunciados constatativos y realizativos en el discurso administrativo para la construcción de organizaciones lucrativas
}

David Galicia Osuna

Facultad de Estudios Superiores Cuautitlán, UNAM

david53@fesc.cuautitlán2.unam.mx

\section{Resumen}

El objetivo de este ensayo es mostrar, desde la semiótica y la pragmática, dos tipos de enunciados que componen al discurso administrativo: enunciados constatativos y no constatativos; estos últimos nos permiten hablar de la intencionalidad en la construcción de organizaciones lucrativas, lo que nos hace responsables de ellas, pero también de su posible renovación con un sentido más humano, como ya señala Omar Aktouf. Se propone que en el discurso administrativo hay dos tipos de enunciados que conforman al discurso administrativo: enunciados constatativos (o verificativos), y principalmente enunciados realizativos (Austin, 1971). Los primeros buscan la verdad; los segundos, desde una perspectiva pragmática (Rorty, 1993), la eficacia (Searle, 1999) para construir una organización.

Palabras clave: discurso administrativo, oraciones constatativas y realizativas. 


\title{
The constative and performative statements in the administrative discourse for the constructions of profit organizations
}

\begin{abstract}
This essay's objective is to show, from the semiotic and pragmatic points of view, two types of statements that make up the administrative discourse: constative statements and non constative statements. The latter allow us to speak of intentionality in building profitable organizations, which holds us accountable for them, but also of its possible renovation into a more humane sense, as Aktouf Omar says. My proposal is that there are two types of statements that make up the administrative discourse: constative or verification statements, and mainly, performative statements (Austin, 1971); the former seek truth, the latter, from a pragamatic perspective, (Rorty, 1993), seek effectiveness (Searle, 1999) to build an organization.
\end{abstract}

Keywords: administrative discourse, constative and performative sentences.

\section{Introducción}

Lakatos decía que una nueva teoría válida nos permite ver algo que antes no veíamos. Uno de los objetivos básicos de este ensayo es mostrar dos tipos de enunciados que componen al discurso administrativo: constatativos y performativos. Con esta distinción nos sumamos a los estudios críticos de la gestión ${ }^{1}$, pero desde otra perspectiva. La tradición de la escuela de negocios, en su afán de brindar herramientas conceptuales a los directivos al formar profesionales capaces de gestionar y administrar una empresa, no puede percibir ${ }^{2}$ en particular por la tradición en la que se encuentra inscrita; es el caso de la tradición que sigue el modelo descriptivo norteamericano como Koonz o Terry, en general, de las business schools. Por ello, en este trabajo se propone que en el discurso administrativo hay dos tipos de enunciados que conforman al discurso administrativo: enunciados constatativos (o

\footnotetext{
${ }^{1}$ Hay que reconocer que los estudios críticos de la gestión no sólo vienen de los Critical Management Studies, como es el caso de Omar Aktouf. Los estudios críticos no sólo toman a Foucault o Habermas, como marco teórico. Por mi parte, reconozco mi influencia de la filosofía política de la Escuela de Cambridge, de pensadores como Quentín Skinner, Sheldon Wolin, Leo Strauss, John Dunn, J.A. Pocock y Hanna Arendt (ver Velasco, 1999).

${ }^{2}$ Ver los estudios de los Critical Management Studies, atendiendo en particular el panóptico de Foucault en Vigilar y castigar o la Teoría de la acción comunicativa de Habermas.
} 
verificativos), pero principalmente de enunciados realizativos (Austin, 1971); los primeros buscan la verdad; los segundos, la efectividad para construir una organización. Además, los enunciados de tipo no constatativos (los realizativos) son de mayor importancia para la creación ${ }^{3}$ de una organización.

Es importante aclarar que por discurso administrativo entendemos una estructura conceptual prescriptiva ${ }^{4}$, más que explicativa y predictiva; en términos de Kuhn (2007) conformaría un periodo de ciencia normal; en Lakatos (1983), un programa de investigación; y en Laudan (1977), una tradición de investigación; nos referimos a las llamadas funciones de la administración (Koontz, 1998) o proceso administrativo (Reyes, 2004).

En los enunciados que conforman este discurso administrativo se puede hacer una distinción de enunciados: del tipo constatativo o verificativo y del tipo realizativo, ambos desde una perspectiva pragmática ${ }^{5}$, y del pragmatismo; en este sentido y siguiendo a Rorty (1993), quien señala: "volvernos pragmatistas, identificar el sentido de la vida con obtener lo que se desea, con imponer nuestra voluntad; donde las categorías de la razón no deben perder de vista sus fines utilitarios". El énfasis en los enunciados realizativos puede seguir la inquietud responsable de Omar Aktouf $(2001)^{6}$ para pasar de una administración tradicional a una administración renovada, es decir, hacer una administración más humana.

\footnotetext{
${ }^{3}$ En este sentido, nos ubicamos en la perspectiva construccionista trabajada por algunos sociólogos como Bourdieu, Norbert Elías, Anthony Giddens, Peter Berger y Thomas Luckman.

${ }^{4}$ Existe un interesante estudio de Ríos (1997), quien propone desechar el modelo prescriptivo por secuencial y por parecerle una receta reduccionista; sin embargo, por un lado, desconoce el potencial poético de tales enunciados (los prescriptivos); y, por otro, llama la atención que no desecha el modelo prescriptivo por lo que la tradición positivista normativa señalaba, que una teoría científica no puede hacerse con enunciados prescriptivos, sino necesariamente descriptivos-verificables. Criterio ahora ya superado.

${ }_{5}^{5}$ La pragmática como una parte de la semiótica que estudia la relación enunciado-acción.

${ }^{6}$ De acuerdo con Aktouf, hay una serie de "verdades" —o palabras realizativas en el lenguaje de Austin y Searle_-que han permitido construir y determinar acciones injustas. De ahí la responsabilidad de las palabras por sus efectos en construir realidades. Aktouf señala algunas palabras que hacen realidades como la propiedad privada, hecha institución; los derechos naturales conferidos al dueño de la propiedad; la maximización de la ganancia, vía productividad, que se considera en la racionalidad económica y en las teorías de desarrollo económico; la división social y técnica del trabajo, que requiere de mayor inteligencia; la degradación del empleado. Aktouf ya señala palabras que hacen cosas inhumanas, injustas, no preocupadas sino por la propiedad privada, no por el bien común. En efecto son dogmas, pero —-más allá del problema de la verdad o falsedad— son efectivas.
} 
En particular, los enunciados realizativos o performativos ${ }^{7}$ vienen de una obra de Austin (1971), que puede aplicarse desde nuestra perspectiva al discurso administrativo. Esta obra se titula How to Do Things with Words, que hace referencia a la fuerza de las palabras, más allá del criterio de verificación, contrastación o falsación y verdad de corte positivista. Aquí la "verdad" de una palabra o proposición no se da por su relación con las cosas — semántica— sino con la acción — pragmática. Las palabras no sólo tienen una función de representación de la realidad, sino que también tienen efectos en la acción humana. ${ }^{8}$ Además de la relación que tienen las palabras con las cosas, que nos lleva al problema de la verdad de una proposición, también tienen relación con las palabras y/o enunciados con la acción ${ }^{9}$ y, por ello, con la efectividad.

\begin{tabular}{c|c|c|c|c}
\hline No. & \multicolumn{3}{|c|}{ Relación } & Medida \\
\hline 1. & Palabra & Enunciado & $\begin{array}{c}\text { Con cosa } \\
\text { Objeto }\end{array}$ & $\begin{array}{c}\text { Verdad } \\
\text { o } \\
\text { Falsedad }\end{array}$ \\
\hline 2. & Palabra & Enunciado & $\begin{array}{c}\text { Con } \\
\text { acción }\end{array}$ & Efectividad \\
\hline
\end{tabular}

Planeación, organización, integración, dirección y control son palabras que pueden tener relación con la verdad, pero quizá más importante es su relación con la acción y la efectividad ${ }^{10}$. Al discurso administrativo lo conforman un conjunto de palabras

\footnotetext{
${ }^{7}$ Ya en la teoría de los actos del habla, Austin y Searle hablaban de actos, de fuerza y efectos ilocucionarios y perlocucionarios, que más adelante se comentará.

${ }^{8}$ De hecho podemos considerar en este campo enunciados para hacer utopías, ficción, críticas, retórica, distopías, estudios argumentativos, evaluaciones, novela, poesía, normas, valores, metas, no sólo amenazas, promesas, alabanzas, ofensas, sueños e ilusiones. Enunciados un tanto alejados de la preocupación empirista, pero que llegan a tener efectos en la realidad, hacen realidad social.

${ }^{9}$ En este sentido, los norteamericanos al trabajar con el modelo teórico-descriptivo desde una visión "así es", nos permiten considerar valores, normas, prescripciones que hacen posible las empresas. Se da juego a la irresponsabilidad, que ya Herbert Simon supera. El modelo descriptivo no permite ver la responsabilidad que tenemos de hacer organizaciones. El modelo prescriptivo posibilita ver nuestra responsabilidad. Se debe rebasar la separación de juicios de hecho de juicios de valor. Omar Aktouf propone, en este sentido, pasar de una administración tradicional a una renovada.

${ }^{10}$ En efecto, una perspectiva semejante y muy enriquecedora la podemos encontrar en los estudios de los Critical Management Studies. Desde marcos conceptuales como la teoría crítica, Habermas en su Teoría de la acción comunicativa, en particular, nos ofrece conceptos en este sentido. Foucault con su concepto panóptico disciplinario permitía ver en Vigilar y castigar (2005) esta problemática y en su obra Tecnologías del yo (2000) nos encontramos con este sometimiento y construcción de patrones de acción.
} 
que forman una peculiar estructura que, más que la coherencia teórica tradicional, busca la efectividad, los logros de ciertos objetivos organizacionales. Cómo hacer cosas con palabras, es una afirmación que señala la efectividad de las palabras para producir hechos institucionales; es el caso de las palabras: planeación, organización, integración y control.

Las palabras —además de estar en formas enunciativas descriptivas que permiten hablar de verdad o falsedad en las teorías que maneja dicho discurso- también pueden estar en formas enunciativas, argumentativas, retóricas, exclamativas, prescriptivas, imperativas e interrogativas que condicionan la acción humana; esto a diferencia de los criterios de cientificidad, positivistas lógicos y neopositivistas que no aceptan como enunciados aquellos con los que se pueda hacer ciencia.

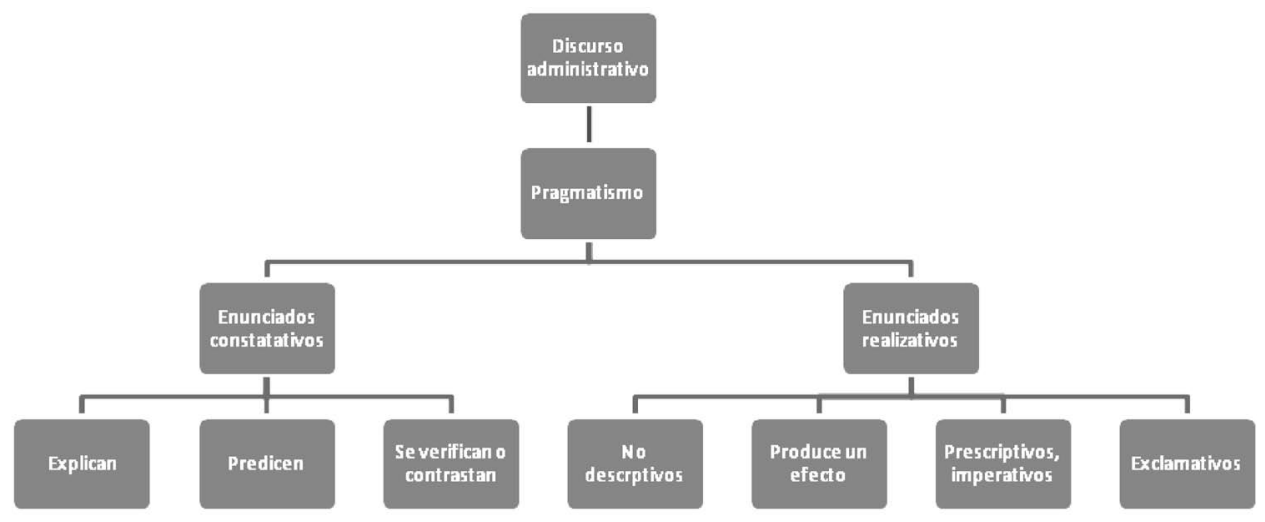

Frente a la propuesta de una ciencia no normativa, que quería identificarse con los métodos de las ciencias naturales, cuantitativas y apegadas al dato, la teoría de los actos del habla nos lleva por otro camino. No es posible separar para nosotros conocimiento de valor, ni tampoco conocimiento de emoción, ni reducirnos a enunciados descriptivos para comprender lo que pasa en las organizaciones sociales.

\section{Enunciados constatativos}

Durante la hegemonía del empirismo y positivismo lógico se había supuesto que el único criterio para que un enunciado fuera considerado significativo era que se pudieran constatar, o verificar, contrastando enunciados descriptivos (leyes o hipótesis) con respecto a hechos. Así, los enunciados que importaban eran los que se 
les podía predicar verdad o falsedad, lo demás era metafísica ${ }^{11}$. Se tomaban como verdaderos si representan correctamente la realidad y falsos si no lo hacían; esto se puede constatar por los criterios de cientificidad de los filósofos de las ciencias empiristas, positivistas lógicos o neopositivistas.

El horizonte de percepción de esos pensadores se había enriquecido con diversos conceptos que definen lo que tenía sentido y lo que no (Russell, 1905), tal fue el concepto de verificación o constatación cuyo origen se encuentra en el Círculo de Viena; sin embargo, es necesario algunos de los conceptos que conforman el horizonte de percepción del positivismo lógico en el discurso administrativo.

Retomemos algunos elementos de Kliksberg (1990) de su texto El pensamiento organizativo, que tiene la intención de dar aportes desde un esquema neopositivista para la construcción de la teoría de la administración, lo cual nos permite retomar algunos de sus conceptos que pueden ser ilustrativos.

Es interesante el señalamiento de este autor acerca de que la administración se puede ubicar tanto en el ámbito científico como en el técnico, pero no como arte. Al final de cuentas, lo que para algunos teóricos de la administración consideran como arte (Koontz Harold y Weihrich Heinz, 1998, p. 13) en el discurso administrativo se refiere a la técnica, lo cual se puede ver cuando se define el concepto de arte.

Kliksberg considera que los fenómenos de la naturaleza y la sociedad no se producen de forma anárquica e intermitente, sino que pueden hallarse regularidades de algún orden. Esto permite producir conocimientos y poder dar explicaciones y predicciones acerca de la realidad natural y social. La explicación, como la predicción, obedece a una dinámica causal, especialmente eficiente; ello posibilita a los científicos establecer leyes generales y teorías que permiten explicar y predecir fenómenos. En particular, en la predicción podemos verificar o constatar una proposición a la que llamamos hipótesis, la cual puede ser verdadera si representa objetivamente la realidad o falsa si no se verifica; por ello, considera que contamos con un buen criterio de demarcación entre un enunciado confiable del que no lo es y entre enunciados científicos de los que no lo son.

\footnotetext{
${ }^{11}$ Sabemos por Carnap, Hempel, Russel, Popper, en general, los positivistas lógicos, que el término metafísica representaba toda aquella creencia que no era considerada científica, que su criterio de demarcación verificacionista o falsacionista no se le podía aplicar.
} 
Por otra parte, mediante la aplicación del método científico, la tarea del científico culminará con la obtención de hipótesis, leyes, teorías, que permitan la explicación y predicción de la realidad, las cuales se validan conforme a los criterios de verdad o adecuación empírica. El grado de veracidad de las proposiciones se obtiene por su potencialidad de verificación; esto lo muestra la frontera de la ciencia positiva. Los enunciados como las teorías, leyes e hipótesis que permiten explicar y predecir hechos son los que hemos llamado constativos y que en el discurso administrativo los encontramos en algunas de las teorías que maneja, en particular en algunas teorías motivacionales. Resumiendo, los conceptos importantes del conocimiento científico pueden ser:

- El conocimiento científico de teorías no crea las cosas que componen la realidad. Busca explicarla y proponer predicciones contrastables empíricamente.

- La realidad es explicable. El mundo tiene una estructura, una armonía, que muestra regularidades, lo cual posibilita la creación de la ciencia, al describir tales regularidades en enunciados con la forma de hipótesis, leyes y teorías.

- El conocimiento científico, basado en los enunciados constatativos o verificativos, tiene como meta la explicación y la predicción de fenómenos.

- La tarea científica se desenvuelve por la aplicación del método científico.

La idea de que el conocimiento científico no crea la realidad viene dada desde el empirismo lógico de Bertrand Russel (1991), quien afirma de forma interesante: "El mundo de la razón en cierto sentido fiscaliza el mundo del hecho, pero de ningún modo es creador de hechos". Muy en la vieja tesis que ya desde el racionalismo de Leibniz y Kant criticaban; la mente es como espejo; la ciencia representa la realidad; sin embargo, los racionalistas ya habían señalado que la mente no es pasiva, sino activa.

Desde otro horizonte de percepción, consideramos que la mente humana es activa, que la razón humana tiene la posibilidad de crear hechos y realidades (en este caso sociales), como señalaban Thomas Luckmann y Peter L. Berger (1967, 2008, pp. 64-117) en su texto La construcción social de la realidad, cuando nos hablan de las instituciones. Indudablemente, toda sociedad —en particular sus organizaciones - son construcciones humanas en función del lenguaje donde la razón y la emoción tienen que ver. 


\section{Enunciados realizativos}

Con respecto al uso del lenguaje surgen algunas preguntas: ¿qué es lo que en realidad hacemos con el lenguaje? El lenguaje ¿puede crear hechos sociales y condicionar acciones? ¿Cómo es que lo usamos socialmente? ¿Cómo se relaciona el lenguaje con el mundo? y ¿Cuál es el propósito del lenguaje? ¿Cómo se construye la realidad social? (Searle, 1977).

Desde luego el lenguaje tiene relación compleja con la creación del mundo social, como apunta bien Searle (1997) en su texto La construcción de la realidad social, en particular de sus organizaciones, cuyas regularidades, hábitos, estructuras o patrones están soportadas por el lenguaje, muchas veces prescriptivo. De igual forma, el lenguaje $\mathrm{j}^{12}$ lo usamos para representar como para prescribir, planear, influir, manipular, determinar ${ }^{13}$.

Para la creación de hechos y realidades sociales participan tanto los enunciados científicos, los cuales se verifican o constatan en la realidad para considerarlos como verdaderos; pero especialmente los enunciados realizativos que consideran como verdad la efectividad. Berger y Luckmann (1979) señalan que la construcción de la realidad social es un proceso de institucionalización de las prácticas y de los roles de la vida cotidiana, aunque desde una perspectiva diferente a la de Searle, pues esos autores consideraban fundamentalmente el conocimiento porque desconocían la teoría de los actos del habla de Austin y Searle.

Así, además de los enunciados que constatan hechos, hay enunciados importantes que no constatan hechos, no describen hechos, pero que no dejan de ser importantes; son enunciados que establecen relación, no entre palabras y cosas, sino entre palabras y acciones, entre enunciados y patrones de acción social. Hablamos de

\footnotetext{
${ }^{12}$ Searle nos dice que la realidad social es construida desde tres factores: la asignación de funciones a objetos; las reglas constitutivas y la intencionalidad colectiva. Todas son importantes para entender cómo creamos hechos sociales, aunque se destaca la intencionalidad colectiva; ésta nos habla de que compartimos conductas cooperativas, pero a diferencia de los otros animales que lo hacen por instinto, lo hacemos por compartir creencias, deseos, motivos, visiones, misiones, intenciones conscientes. Añadiría que éstos son históricos, dependientes de alguna tradición discursiva en el sentido de Larry Laudan o Alasdair MacIntyre. Intencionalidad colectiva diferente a la intencionalidad individual (ver Searle, 1997, pp. 41-44).

${ }^{13}$ Como se señaló arriba y como referente de los Critical Management Studies, Foucault en Vigilar y Castigar con su concepto de panóptico — técnica disciplinaria - mostraba una forma de estudiar el control y la resistencia, elemento de la nueva cultura corporativa.
} 
enunciados exclamativos, interrogativos, prescriptivos, evaluativos, críticos, utópicos retóricos, argumentativos, persuasivos, distópicos, ideológicos, de ficción, que prometen, que amenazan, que son emotivos, que son valorativos y que hablan de lo que debe ser.

La teoría de los $\operatorname{actos}^{14}$ del habla amplía el campo de lo que tiene sentido. Los enunciados prescriptivos, las normas, las políticas, las promesas, los imperativos, las amenazas, que no están regidos por la dicotomía verdadero/falso, están regidos por lo que realizan (perform), por lo que efectúan y como una determinada acción; además, se miden por su efectividad, desde normas, políticas, prescripciones, creando patrones de acción a través de la aceptación y obediencia de ciertos valores y normas.

Así, el lenguaje tiene — además de una función representativa, que la ciencia y la filosofía de la ciencia positivista habían señalado como el lenguaje con sentidonuevas funciones por considerar, que hacen de él una herramienta compleja y polifacética en manos del ser humano. Esto es, el lenguaje tiene un uso performativo con éxito, como una promesa cumplida, una amenaza, un objetivo alcanzado, una ficción, así como la prescripción de una estructura organizacional o una norma que guía una acción y que lleva a realizar un valor.

Pero los actos del habla tienen sus problemas. Como estrategias ${ }^{15}$ pueden remitir a producir algo, una estructura injusta (Weber, 1999) y reproducir una situación no democrática ${ }^{16}$, que olvide el consenso (Habermas, 1989), la razón y la argumentación por el interés egoísta. Ello lo podemos encontrar en repetidas ocasiones en las organizaciones que sólo buscan lucro y son verticales.

\footnotetext{
${ }^{14} \mathrm{La}$ teoría de los actos del habla, formulada por Austin (1971) y por Searle (1977), permiten reconocer la dimensión accional del lenguaje. Muestran cómo el lenguaje y las acciones se conectan. Prestan especial atención a las intensiones del hablante para determinar acciones. Conceptos como actos y efectos ilocucionarios, así como actos y efectos perlocucionarios, son básicos para entender la relación de palabra acción. Austin estudia la relación entre las formas lingüísticas y las acciones; para él, los actos del habla son la realización de tres tipos de actos: acto locucionario, acto ilocucionario — relación de lo dicho con la fuerza convencional o fuerza ilocucionaria $-\mathrm{y}$ acto perlocucionario, acto conseguido por decir algo. Los efectos perlocucionarios son ciertas consecuencias o efectos en sentimientos, pensamientos o acciones del auditorio, además de la comprensión del significado de las palabras.

${ }^{15}$ Cruz Soto (2010) ya propone que lo que debe definir a la autoridad es la legitimidad, desde la perspectiva aristotélica, entendida como dominación legítima: "Entenderemos como legitimidad de la autoridad el reconocimiento racional, informado y voluntario de los miembros en la aceptación de un mandato".

${ }^{16}$ Ver "Los tipos de dominación" de Weber (1999, pp. 170-241).
} 
Dos tipos de actos del habla dentro de la teoría de los actos del habla sobresalen: ilocución y perlocución, que es más que una locución o emisión de un enunciado. Se refieren a realizar una operación y a la producción de un efecto. Son enunciados con fuerza, ilocusionaria o perlocusionaria; ejemplos de ambos son:

- Actos del habla ilocucionarios. Consiste en emitir palabras dentro de oraciones en ciertos contextos, bajo ciertas condiciones y con ciertas intenciones. Pedir, prescribir, evaluar, criticar, imaginar, prometer, normar, aconsejar, advertir, amenazar o saludar. La forma normal para realizar actos ilocucionarios consiste en utilizar un verbo realizativo o ilocucionario en la primera persona singular del presente indicativo y voz activa ${ }^{17}$.

- Actos del habla perlocucionarios. ${ }^{18}$ Son un subconjunto del anterior: refiere a aquellas palabras o enunciados que tienen la noción de consecuencias o efectos que tales actos tienen sobre las acciones, pensamientos o creencias.

\footnotetext{
${ }^{17}$ Verbos realizativos como condenar, absolver, estimar, declarar, evaluar. También verbos como ordenar, instar, aconsejar prevenir; otros como prometer, garantizar, comprometer, jurar, apostar; negar, conceder, observar, ejemplificar; verbos imperativos como mandatos, así como proponer, preguntar o enunciar. Ejemplos: 1. A tres días de la apertura de los Juegos Panamericanos de Río de Janeiro se multiplicaron las amenazas de paralización y las huelgas de funcionarios públicos que quieren aprovechar el evento deportivo para fortalecer sus reivindicaciones laborales. 2. Como es sabido, el Estatuto de los trabajadores permite a los empleadores adaptar la dimensión de la plantilla de la empresa o las condiciones de trabajo de sus empleados a las necesidades de la organización empresarial con base a circunstancias económicas, técnicas, organizativas o productivas. 3. El sentimiento generalizado entre los miembros del Sindicato Mexicano de Electricistas (SME), de orgullo por su Contrato Colectivo de Trabajo (CCT), expresa la lucha que han librado por décadas contra diversos patrones y gobiernos. 4. La Declaración de la OIT relativa a los principios y derechos fundamentales en el trabajo obliga a los Estados Miembros a eliminar el trabajo forzoso. Una relación de trabajo debería elegirse libremente y sin que pesen amenazas sobre ella. 5. Respuesta de Azcárraga Jean después del rescate financiero de Televisa: “-Mire ingeniero -Slim-, nosotros ya le pagamos puntualmente el préstamo [...] Quienes deciden lo que se hace en los contenidos de Televisa somos nosotros". Disputa Telmex-Televisa.

${ }^{18}$ Algunos ejemplos de ellos: 1) Martin Luther King: "Sueño que un día, en las rojas colinas de Georgia, los hijos de los antiguos esclavos y los hijos de los antiguos dueños de esclavos, se puedan sentar juntos a la mesa de la hermandad". 2) Marx, Tesis XI sobre Feuerbach: "Los filósofos no han hecho más que interpretar de diversos modos el mundo, pero de lo que se trata es de transformarlo". 3) Russell Crowe, Gladiador: "Si os veis cabalgando solos por verdes prados el rostro bañados por el sol. Que no os cause temor, estaréis en el Eliseo y ya habréis muerto. Hermanos lo que hacemos en la vida tiene su eco en la eternidad". 4) Maquiavelo, El Príncipe: ¿Qué vale más ser temido o amado? Los corruptos no le temen a Dios, mucho menos a los hombres; los corruptos representan un peligro para un príncipe, sólo piensan en adquirir fortunas rápidas y fácilmente adquiridas sin importar el daño y las secuelas que provocan en las instituciones que dirigen; "Es necesario, por tanto, ser zorra para conocer las trampas, y león para amedrentar a los lobos”. 5) Lady Macbeth: “[...] venid a mí, espíritus que servís a propósitos de muerte, quitadme la ternura y llenadme de los pies a la cabeza de la más ciega crueldad. Espesadme la sangre, tapad toda entrada y acceso a la piedad para que ni pensar ni incitación al sentimiento quebranten mi fiero designio, ni intercedan entre él y su efecto. Venid a mis pechos de mujer y cambiad mi leche en hiel, espíritus del crimen, donde quiera que sirváis a la maldad en vuestra forma invisible."
} 
La realización de un acto perlocutorio típico depende de la producción de efectos, como el caso de las palabras planeación, organización, dirección y control o como verbos: planear. organizar, dirigir y controlar ${ }^{19}$.

La fuerza ilocusionaria refiere la intención de realizar un efecto con los enunciados o palabras. Son dispositivos que posibilitan crear hechos institucionales desde una intencionalidad colectiva, una conducta o una acción, como una organización social determinada, no natural.

En esta propuesta se pretende hacer énfasis en el papel creador de los actos del habla de la influencia (Velasco, 1999) que pueden tener en la acción, en la creación de hechos, de procesos y de regularidades. En este sentido es importante decir que dichas palabras o enunciados tienen una intención.

La causalidad a la que hago mención es muy particular; no es una causalidad natural. El sonido de las olas del mar es diferente al sonido del habla humano, no tiene intencionalidad el mar de decirnos algo, igual el sonido del aire. Pese a que podemos interpretar, dar sentido y significado a dichos sonidos, el mar y el aire no tienen la intención de comunicarnos algo. La marca que deja una erosión en una piedra no se compara con un jeroglífico maya o egipcio. Las marcas de los mayas y egipcios, como el decálogo bíblico en las piedras que mostró Moisés al pueblo judío, tuvieron una intención de comunicación y, en este caso, determinar un patrón de acción deseable. De igual forma, una organización es una estructura intencional, no natural, creada desde el lenguaje como la planeación y la organización.

Un acto del habla ilocucionario, que absorbe a los perlocucionarios, tiene al menos cuatro elementos básicos: tener reglas, ser una proposición, tener un significado y tener una intención: esto mismo encontramos en el discurso administrativo al planear, organizar, dirigir y controlar (Searle, 1999).

\footnotetext{
${ }^{19}$ Técnicamente el término intencionalidad para Searle (1999, p. 26) refiere a aquel rasgo de la representación en virtud del cual esas representaciones son acerca de algo, están dirigidas a algo. Creencias y deseos son intencionales, además de pretender algo, que pueden conformarse con coincidir (enunciados constatativos) o pueden buscar (enunciados realizativos) que la realidad se ajuste a mi deseo; o también la intencionalidad es aquella característica de un gran número de estados y procesos mentales gracias a la cual esos estados y procesos están dirigidos a o son acerca de objetos y estados de cosas en el mundo; para Searle, no todos los estados y procesos mentales son intencionales, como la ansiedad, la depresión, a diferencia de las creencias, deseos o juicios.
} 
Reglas. Consideremos dos tipos de reglas, las que regulan conductas existentes, como las relaciones interpersonales, que pueden establecer diferentes formas de estas relaciones; por otro lado, las que además de regular crean y definen nuevas formas de conducta, como las reglas de futbol, estas reglas crean al futbol, el futbol no existe aparte de estas reglas. Las primeras (Searle, 1999) refieren a reglas regulativas, mientras que las segundas refieren a reglas constitutivas. Las regulativas regulan una actividad preexistente; las constitutivas constituyen y también regulan una actividad cuya existencia es lógicamente dependiente de las reglas.

El habla ilocucionaria en administración actúa conforme a reglas constitutivas, además de que regula una actividad ${ }^{20}$. Son constitutivas de una organización, así como de su acción regulada, formal e informal porque prescribe un patrón estructural formal, conjuntos de tareas y acciones, y objetivos. Ello lo logra mediante los diversos enunciados que podemos encontrar en las funciones como planeación organización, dirección y control.

Proposiciones. Los actos ilocucionarios pueden tomar diferentes formas enunciativas, como pregunta, afirmación, expresión exclamativa, expresión de un deseo, orden; en general, puede cobrar la forma descriptiva, imperativa, prescriptiva, exclamativa, interrogativa, crítica, evaluación, pero siempre con fuerza ilocucionaria con la intención de producir un efecto, una acción, más que buscar ser una proposición verdadera o falsa.

En el habla ilocucionaria del discurso administrativo podemos encontrar enunciados de diverso tipo además de los enunciados científicos, tales como enunciados interrogativos, imperativos, prescriptivos, normativos, exclamativos. Es el caso de la misión, objetivos, estrategias, políticas de la planeación; de normas y prescripciones en la organización; de motivación, liderazgo y comunicación en dirección; y de las técnicas de control. Aquí las proposiciones cobran la forma normativa, prescriptiva, imperativa, interrogativa, evaluativa, intencional y teleológica, entre otras.

\footnotetext{
$\left.{ }^{20} 1\right)$ Misión de Televisa: Satisfacer las necesidades de entretenimiento e información de nuestras audiencias, cumpliendo la vez con nuestras exigencias de rentabilidad a través de los más altos estándares de calidad, creatividad y responsabilidad social. 2) Una organización racional debe escoger los medios más eficientes para la implementación de las metas; los miembros individuales son parte del engranaje de la máquina organizacional. 3) Perfiles de puesto: director general, director comercial, director de producción. Ello incluye: misión de puesto, funciones principales, tareas relacionadas, competencias deseables, posición en el organigrama. 4) El humano debe buscar de forma persistente y sistemática la maximización de la ganancia, vía productividad.
} 
Significado. Un acto de habla no es una mera marca en un papel o piedra, ni un ruido emitido por una voz. Son marcas o sonidos con significado. Una persona quiere decir algo mediante esos sonidos o marcas. Paul Grice (1968) nos dice que un sonido o marca tiene un significado cuando A quiere decir algo mediante $\mathrm{X}$, es decir, A intentó que la emisión de $\mathrm{X}$ produjese algún efecto en un auditorio por medio del reconocimiento de esta intención.

$A$ es el administrador ${ }^{21}, X$ son el conjunto de proposiciones que constituyen la planeación (la misión, los objetivos, las metas, las estrategias); la estructuración (estructura formal, departamentalización, tareas, autoridad); dirección (motivar, liderar, comunicar); controlar (técnicas de control). Finalmente, está el auditorio que viene a representar a los subalternos, en los que se busca un efecto o acción por medio del reconocimiento de un auditorio u operarios. En una relación intersubjetiva (Habermas, 1989), como el diálogo, tendríamos que considerar, en sentido inverso, el proceso señalado.

Intención. La noción de significado tiene relación con el concepto de intención. El lenguaje humano es intencional ${ }^{22}$, se dirige a alguien. Al hablar un lenguaje intentamos comunicar cosas a nuestro oyente consiguiendo que él reconozca la intención de comunicar precisamente esas cosas y producir un efecto, una acción. Cuando realizamos una aserción intentamos comunicar a, convencer a nuestro oyente de algo, intentamos producir algún efecto. Con una marca o sonido intentamos producir un efecto en él o en ellos. En esta relación puede darse el habla estratégico o consensuado.

Hablar de los estados intencionales, como parte de los procesos mentales, nos lleva de nuevo al problema de la conciencia. Searle, dentro de la investigación en filosofía de la mente, señala que nos hemos olvidado de la conciencia y sus capacidades. Él vuelve a la intencionalidad de los estados mentales, pues propone volver a tratar la subjetividad de los estados conscientes. Asimismo, Searle (1983) afirma que conciencia e intencionalidad están unidas. Cualquier estado intencional es potencialmente o de hecho un estado intencional consciente.

\footnotetext{
${ }^{21}$ Chester Bernard (1959) critica estos modelos de dirección donde las cúpulas mandan y los subalternos obedecen. (Ver Las funciones de los elementos dirigente).

${ }^{22}$ Cruz Soto (2010) nos habla del comportamiento administrativo como intencionado, orientado hacia metas y objetivos. (Ver "El concepto de autoridad en el pensamiento de Aristóteles y su relación con el concepto de autoridad en el comportamiento administrativo").
} 
La intencionalidad para Searle (1997) es aquella característica de un gran número de estados mentales gracias a la cual esos estados y procesos están dirigidos a o son acerca de objetos y estados de cosas en el mundo. Es decir, no todos los estados o procesos mentales son intencionales, pertenecen a la esfera de los sentimientos como el nerviosismo, ansiedad, depresión, júbilo. Hay estados mentales intencionales como las creencias y los deseos y responden a preguntas ¿qué crees?, ¿qué deseas? Siempre se cree y se desea algo, no en nada.

Los estados mentales intencionales se pueden comparar con la estructura de los actos del habla. Un estado mental intencional es representacional, pero puede tener diversos modos psicológicos. Así, una creencia un juicio o deseo puede representar algo. Podemos creer en algo, con una dirección de ajuste mente-mundo o podemos tener una dirección de ajuste mundo-mente. En un primer caso, el contenido representativo tiene que conformarse o coincidir con el mundo, como es el caso de los enunciados constatativos, la dirección de ajuste se caracteriza por ser mundo-mente. Si, por el contrario, deseamos que se dé algo o que no se dé, si no nos gusta algo y deseamos cambiarlo, la realidad es la que debería ajustarse a nuestro deseo; en este caso nuestros deseo ha de realizarse. Para estos casos de intencionalidad convienen los enunciados no constatativos, los realizativos; por ejemplo, cuando se dice que una creencia (González, 1992) es una representación, es decir, que tiene un contenido proposicional que determina la dirección de ajuste. Las proposiciones o enunciados pueden ser constatativos o realizativos; en este sentido, sería lo mismo para Searle hablar de contenido proposicional, contenido representacional o contenido intencional. La dirección de ajuste que proponemos cuando se habla de intencionalidad no es tanto la de mundo mente, sino la de mente mundo, donde nuestra representaciones o proposiciones no constatativas crean hechos sociales, instituciones sociales, organizaciones humanas, realidad social.

Finalmente, el objeto intencional de un estado mental o representacional es aquello a lo que el estado mental está dirigido; aquello a lo que está dirigida con sus condiciones de satisfacción tal y como están determinadas por el contenido intencional de dicho estado mental. Un estado mental intencional está dirigido a su objeto intencional, el cual satisface el estado intencional. La función de satisfacción que tiene el objeto intencional sólo la puede cumplir cuando satisface el contenido intencional del estado intencional en cuestión. El objeto que satisfaga el estado mental puede ser o representacional mundo-mente o mente-mundo. En el segundo caso es cuando el objeto puede ser creado desde la subjetividad humana, de acuerdo con 
los enunciados o proposiciones señalados en los actos del habla; desde luego es un objeto creado intencionalmente como los hechos institucionales: el mercado, el matrimonio, la propiedad privada, una organización lucrativa.

En el caso de la planeación, organización, integración, dirección y control, se habla de actos del habla considerando la semántica, en oraciones gramaticalmente bien formadas.

El hablante $\mathrm{H}$ emite una oración $\mathrm{O}$ en presencia de un oyente $\mathrm{S}$, entonces en la emisión O, H sinceramente planea, organiza, dirige, controla, con O a S. Sin duda, este modelo hace una organización no democrática y dialógica, vertical y burocrática en el sentido del modelo burocrático de Weber (Chiavenato, 2007, pp. 221-230).

\section{Los otros tipos de enunciados en el discurso administrativo}

En el discurso administrativo no sólo vamos a encontrar enunciados descriptivos, como pretende hacer ver la tradición del modelo descriptivo estadunidense (Koonz, Terry, C. O`Donnell), que respondan a la verificación como lo señalan los positivistas lógicos. Pese a los esfuerzos de diversos teóricos de la administración, tampoco es posible desde mi perspectiva construir una teoría administrativa ${ }^{23}$, formada por un sistema de leyes de la cual se deduzcan hipótesis, aplicables a la solución de problemas organizacionales. Es decir, me parece que no es posible construir una teoría administrativa solamente con enunciados legaliformes como en la física o cualquier otra ciencia natural, respondiendo a los criterios de teoricidad, fundada en términos teóricos o hipótesis con enunciados que buscan ser verdaderos por contrastación. Desde luego, tampoco puede construirse dicha teoría administrativa buscando una sistematicidad y coherencia lógica semejante a la teoría mecánica newtoneana. Basta observar lo que sucede en tal discurso.

Si nos arriesgamos, podemos considerar como "teoría" administrativa al esquema de cuatro o cinco elementos o funciones, también llamado por los mexicanos —como dice Ríos (1997)— proceso administrativo ${ }^{24}$ : planeación, organización,

\footnotetext{
${ }^{23}$ En efecto, en ciencias sociales y en particular en el discurso administrativos no se pueden encontrar teorías que cumplan las exigencias de la filosofía de la ciencia positivista como las de explicar y predecir fenómenos.
} 
dirección y control, en cualquiera de estas funciones encontraremos proposiciones o que no corresponden, ni pueden contrastarse o verificarse, o presentan problemas de contrastación, como los enunciados prescriptivos. Los enunciados descriptivos permiten explicar y predecir; los enunciados realizativos, en particular los prescriptivos, permiten construir patrones de acción social, diseños organizacionales, como una organización lucrativa. Es importante la predicción, pero más lo es la prescripción para la construcción de una organización humana.

Koontz nos dice que "nos hemos familiarizado con "la teoría básica de la administración y con las cinco funciones administrativas fundamentales: planeación, organización, integración de personal, dirección y control" (Koontz Weihrich, 2001, p. 74). Esto es que la teoría básica de la administración se estructura por estas cinco funciones. Desde nuestra perspectiva dicha teoría permite construir realidades organizacionales prácticas:

\section{- Planeación}

Es la primera función de la teoría de la administración; en ella se pretende garantizar que todos entiendan la visión ${ }^{25}$, la misión ${ }^{26}$, los propósitos y los objetivos, así como los medios para alcanzarlos. La función de la planeación implica la selección de misiones y objetivos, así como de las acciones para alcanzarlos; requiere de toma de decisiones, elección entre cursos de acción futuros y alternativos. Parte fundamental de la planeación son los planes como propósitos o misiones, objetivos o metas, estrategias o políticas, normas. Por ejemplo, en la fase de planeación, cuando se señala la importancia de planear, las misiones, los objetivos, las estrategias, las políticas las normas, se muestran como enunciados prescriptivos

\footnotetext{
${ }^{24} \mathrm{De}$ acuerdo en parte con la importante propuesta de Ríos de que el modelo teórico-descriptivo refiere a funciones, mientras que el modelo técnico-prescriptivo refiere a procesos o etapas, dándose dos modelos distintos. Pero el considerar teoría al primer modelo (al descriptivo) y no al segundo, genera algunas dudas. En el "modelo descriptivo" encontramos enunciados prescriptivos importantes como misión, visión, objetivos, metas, normas, políticas, hablan de lo que debe ser la organización, prescriben, pero ¿por qué llamar teórico a este modelo? Las exigencias positivistas de una teoría se refieren a que puedan explicar y predecir fenómenos empíricos, no de decir lo que deben ser, que pertenece a otro ámbito, lo cual no considera Ríos. Por otro lado, en ciencias sociales me parece que no es posible hacer teorías "puras", ya descriptivas o ya prescriptivas. En lo particular me parece más interesante el modelo prescriptivo que el descriptivo, por no abandonar la responsabilidad de que nosotros hacemos las organizaciones y no simplemente son. Las palabras hacen cosas, patrones de comportamiento, hechos sociales, organizaciones.

${ }^{25}$ Los enunciados que tienen relación con los sueños, las esperanzas, las utopías, la ficción, las distopías son familiares a este concepto.

${ }^{26}$ Misión, visión y valores de Sears: Misión: el cliente es la razón de ser de nuestro trabajo. Visión: consolidar y mantener nuestro liderazgo de nuestra empresa en el mercado. Valores: el trabajo es nuestro valor porque sólo a través de él podemos cubrir nuestras necesidades.
} 
o imperativos. Enunciados que son diferentes a los que propone el positivismo para conformar una teoría, como un sistema de leyes. Como sabemos sólo ciertos enunciados son susceptibles de ser verdaderos o falsos, éstos son los descriptivos, aquellos hablan de lo que es una organización no de lo que debe ser; pero los enunciados prescriptivos son enunciados diferentes a las leyes o hipótesis científicas.

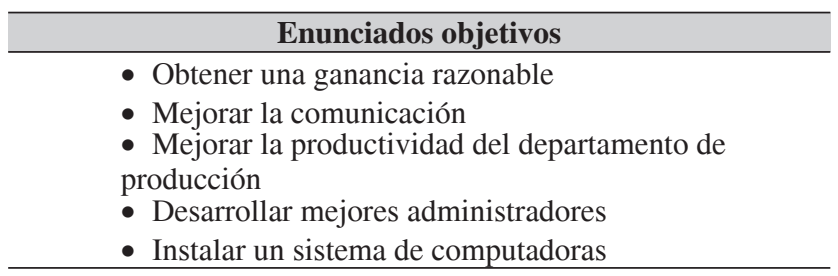

Fuente: Koontz y Weihrich (2001) p. 89

De igual forma, la estrategia se refiere a la determinación del propósito o misión y los objetivos básicos a largo plazo de una empresa, así como la adopción y determinación de cursos de acción y la distribución de recursos necesarios para alcanzar estos objetivos. Los enunciados que se usan para formular fines como para formular políticas o estrategias son del tipo básicamente prescriptivos e imperativos, como instrucción de cursos de acción. Refieren a enunciados imperativos que implican la dirección en la que serán aplicados los recursos humanos, materiales, financieros y tecnológicos con la finalidad de incrementar la oportunidad de lograr determinados objetivos.

Las políticas son enunciados que prescriben de forma general, lo que se debe entender; son enunciados que guían el pensamiento y la acción de los administradores. Muchas veces toman la forma de principios y normas generales. Son enunciados que tienen la intención de dirigir y poner límites a las decisiones.

Los enunciados descriptivos deben ajustarse a la estructura de acción dada por las cinco funciones de la "teoría" administrativa ${ }^{27}$, como el caso de la información obtenida por la matriz FODA o TOWS (Koontz y Weihrich, 1998, p. 174).

Para dirigir la acción se acostumbra a echar mano de enunciados interrogativos en el discurso administrativo. Trabajan como factores de la acción, veamos algunas de estas preguntas:

\footnotetext{
${ }^{27}$ Recordemos que para Koontz el modelo de cinco funciones conforman una teoría administrativa.
} 


\begin{tabular}{cl}
\hline \multicolumn{1}{c}{$\begin{array}{c}\text { Enunciados interrogativos } \\
\text { en el discurso administrativo }\end{array}$} \\
\hline$\bullet \quad$ ¿Los objetivos indican: cantidad, calidad, tiempo, costo? \\
¿Los objetivos también incluyen: objetivos de progreso, de desarrollo \\
personal? \\
¿Los objetivos brindan una retroalimentación oportuna para qué, en un \\
caso necesario, se puedan adoptar medidas correctivas?
\end{tabular}

Fuente: Koontz y Weihrich, 2001, p. 90.

\section{- Organización}

Se refiere a un patrón de comportamiento, a una cierta estructura intencional, no natural, que prescribe, que también se conoce por organización formal creada en función del lenguaje. Quizá para no confundir la estructura de una organización lucrativa o no, conviene llamarle estructuración. Por organización entendemos a una empresa como Cemex, Bancomer o Aurrerá; cada una de ellas tiene una estructura formal. La estructura informal, por lo pronto, la dejaremos de un lado, pues en este caso depende de la existencia de una organización con su estructura formal.

Por organización formal se entiende, en general, la estructura intencional de funciones en una empresa formalmente organizada (Koontz y Weihrich, 1998, pp. 242-373). Actualmente, se dice que la organización formal debe ser flexible; es decir que el orden jerárquico, las tareas departamentales que responden a enunciados que las prescriben, deben modificarse por diferentes razones cuando se requiera. Dicha estructura intencional es creada en función del lenguaje realizativo.

La creación de una estructura organizacional ${ }^{28}$ necesita de enunciados prescripti$\operatorname{vos}^{29}$ como de enunciados imperativos. Nos dice Koontz que para que exista una función de organización y sea significativa para la gente debe incluir:

\footnotetext{
${ }^{28}$ Un plan de negocios, un proyecto guiado por enunciados que muestren una visión. En el caso de Aurrerá, en México los hermanos Jerónimo, Plácido y Manuel Arango concibieron —en términos de Searle relación mentemundo, enunciados realizativos - una forma de vender diferente creando un concepto de autoservicio con artículos domésticos y ropa a precios baratos. El significado de la palabra que eligieron, en vasco significa, adelante. En 1958 la idea se realiza, se crea un hecho social: Aurrerá-Bolivar.

${ }^{29}$ Se prescribe si la organización formal debe ser flexible o no; si debe dar lugar a la creatividad, al reconocimiento individual. Se prescribe la división organizacional, los departamentos, el área de una organización sobre la cual una administración posee autoridad con respecto al desempeño de actividades específicas, también prescritas. Se prescribe los niveles organizacionales y tramos de administración o tramos de control, creándose posibilidades como estructuras organizacionales con tramos estrechos o amplios; los organigramas permiten ver esto.
} 
1) Objetivos verificables (enunciados prescriptivos).

2) Una idea clara de las tareas o principales actividades implicadas, las cuales deben quedar prescritas (enunciados imperativos-descriptivos).

3) Un área de autoridad para que la persona que desempeñe el papel sepa lo que se puede para lograr esas metas (enunciados imperativos).

Los enunciados que deben construir una organización deben prescribir lo siguiente (Koontz y Weihrich, 2001, p. 246):

1) La identificación y clasificación de las actividades requeridas.

2) La agrupación de las actividades necesarias para el cumplimiento de los objetivos.

3) La asignación de cada grupo de actividades a un administrador dotado de autoridad (delegación) necesaria para supervisarlo.

4) La estipulación de coordinación horizontal y vertical en la estructura organización.

La estructura formal de una organización se caracteriza por ser intencional, que desempeña diversas funciones en una empresa organizada. Cabe recordar que lo intencional es la determinación de la voluntad en orden a un fin, dos elementos que el positivismo no acepta, voluntad y fines. Recordemos que el positivismo privilegia la causalidad eficiente sobre la causalidad final. Una estructura formal de una organización se entiende más bien por una explicación teleológica.

Koontz nos dice que la organización implica una estructura de funciones o puestos intencional y formalizada. ¿Qué significa estructura intencional de funciones?

- Que las personas que trabajan en común deben cumplir ciertas funciones. Prescribir-describir lo que es un presidente, vicepresidente, gerentes divisionales, gerentes departamentales [...].

- Las funciones que se piden cumplir a las personas deben diseñarse intencionalmente para garantizar la realización de las actividades requeridas $[\ldots]$.

\section{- Dirección}

Para Koontz es el proceso consistente en influir en las personas para que contribuyan al cumplimiento de las metas organizacionales y grupales (Koontz y Weihri- 
ch, 1998). Para llevar a cabo lo anterior hay que echar mano de las ciencias de la conducta, específicamente de sus tres áreas importantes: motivación, liderazgo y comunicación.

1. Motivación. Administrar implica crear y mantener las condiciones adecuadas para que los individuos trabajen en conjunto a favor del cumplimiento de objetivos comunes. Para ello, contribuye el pedir, convencer, persuadir, influir, prometer, dar consejos, advertir, amenazar, halagar, negociar; es decir, palabras que tienen relación con la motivación. Todos estos verbos se colocan en enunciados que no tienen que ver con la ciencia. Una teoría científica no se constituye con pedimentos, promesas, consejos, advertencias, etc.; ello corresponde a enunciados que más bien buscan la efectividad, la acción. La organización tiene objetivos que alcanzar; por ejemplo, cuando tenemos que mover la acción de las personas para alcanzar$\operatorname{los}^{30}$

Debido a que la motivación humana se basa en necesidades mediante promesas, tratos, negociaciones, pedimentos, promesas, sugerencias, advertencias, órdenes, críticas, evaluaciones, valores, amenazas, podremos motivar a las personas a realizar ciertas acciones ${ }^{31}$; por ejemplo, cómo hacer cosas con palabras. Ciertos enunciados pueden mover impulsos, sentimientos, deseos, necesidades, anhelos y con ello acciones; a través de las palabras y enunciados se puede activar los motivadores que inducen al individuo a alcanzar un alto desempeño, como la amenaza, la sugerencia, el consejo, la descripción de casos que no cumplen con la función que se les ha prescrito. Si alguien desea alcanzar la satisfacción de su requerimiento - alimento para su familia, trabajo, ropa, status, sobrevivencia — tendrá que tener cierto desempeño. La motivación en las organizaciones se hace mediante este tipo de enunciados. Las teorías de motivaciones dan a conocer las debilidades o necesidades de sus trabajadores para poder motivarlos, controlarlos y hacer que rindan lo necesario. Esto tiene relación también con cómo hacer daño con palabras.

\footnotetext{
${ }^{30}$ Las teorías de la argumentación o las teorías de la retórica son ejemplos formales de cómo se usa el lenguaje para mover a la acción buscando persuadir. Un ejemplo aplicado en las empresas es el coaching, como método que consiste en dirigir, instruir, estimular y entrenar a una persona o a un grupo de ellas con el objetivo de conseguir alguna meta o desarrollar algunas habilidades.

${ }^{31}$ Aquí refiero a otro tipo de causalidad no nomológica. La orden, la instrucción, el argumento, pretende ser causa de una acción deseada, pero la relación causa efecto no es necesaria, ni universal, como es el caso de la relación causa efecto de las leyes naturales. Hobbes, por ello, abandona esta causalidad retórica, ideológica, argumentativa, persuasiva, y buscará, ilusamente, en política causalidades, leyes precisas.
} 
2. Liderazgo. Lo explicado anteriormente tiene que ver con el liderazgo ${ }^{32}$, que se refiere a la capacidad de alguien o de un grupo para influir en una persona o un grupo de personas para que se esfuercen "voluntaria" y entusiastamente en el cumplimiento de metas grupales (Koontz y Weihrich, 1998, pp. 530-585). Mediante palabras el líder alienta, fuerza a los individuos a desarrollar la disposición para trabajar, pero con ahínco y seguridad en sí mismos, pese a los salarios y condiciones de trabajo. Las palabras del líder los llevan a sus subalternos a trabajar con pasión, formalidad e intensidad en la ejecución del trabajo. El líder contribuye a que un grupo alcance sus objetivos mediante la máxima aplicación de sus capacidades. Mediante sus palabras empuja, aguijonea, inspira, para cumplir sus metas organizacionales. Las promesas, las amenazas, los sueños, los valores, las descripciones, todo ello unido al manejo de las emociones de sus "seguidores", sus dirigidos, serán elementos básicos del líder. Dichos enunciados y palabras que mueven a la acción no son elementos de la ciencia positivista.

3. Comunicación es la transferencia de información de un emisor a un receptor, el cual debe estar en condiciones de comprenderla (Koontz Harold y Weihrich Heinz, 1998, pp. 586-615). Así, un emisor transmite un mensaje mediante un canal seleccionado a un receptor, evitando el ruido, esperando una respuesta del receptor. El mensaje tendrá un contenido, un significado y una intención. En particular, suponiendo la adecuada sintaxis de los enunciados, el contenido de los enunciados referirá a cierto contenido. En particular la comunicación descendente, pero también la horizontal, diagonal, ascendente, buscan un resultado, una acción. En la comunicación, en una organización, las palabras se relacionan con acciones no con cosas como en la ciencia. El memorando, el oficio, la instrucción, la norma, la política, la misión, las metas, que se comunican, las palabras que se comunican tienen relación con la acción. Vienen a ser como causas que buscan un efecto; son enunciados que prescriben y son imperativos que buscan mover la acción.

\footnotetext{
${ }^{32}$ Como antes señalaba, la retórica, la argumentación o las teorías de la argumentación, tienen un lugar natural en este concepto. Algunos ejemplos: 1. "El pensamiento, la visión y el sueño siempre preceden a la acción”. 2. "Si tengo fe en que soy capaz de realizar tal obra, adquiriré en consecuencia la capacidad de realizarla, aún si no poseía esa capacidad al comenzar". 3. "El hecho de triunfar no consiste en vencer siempre sino en nunca caer en el desánimo". 4. "Si quieres tener éxito, duplica tu porcentaje de fracasos". 5. "Ya sea que pienses que puedes, o que no puedes... están en lo correcto". 6. "Apodérate del día; no confíes en el mañana".
} 


\section{- El control}

Es la función ${ }^{33}$ administrativa que se puede entender como la evaluación o medición y corrección del desempeño con el fin de garantizar que se han cumplido los objetivos de la empresa y los planes ideados para alcanzarlos (Koontz Harold y Weihrich Heinz, 1998, pp. 632-655). El proceso básico de control, nos dice Koontz, implica tres pasos:

1) El establecimiento de normas

2) Medición del desempeño con base en estas normas

3) Corrección de las variaciones respecto de normas y planes

Dentro de los enunciados ilocucionarios antes señalados podemos encontrar cierto tipo de enunciados que la postura positivista sobre concepción de la ciencia no considera significativos, por no ser verificativos; entre ellos se encuentran los enunciados evaluativos (bien-mal), prescriptivos (debe o no debe hacer), imperativos (tiene que hacer, es una instrucción), exclamativos (emociones), valorativos (bueno-malo), entre otros.

Las normas corresponden a enunciados prescriptivos; la medición del desempeño a enunciados evaluativos; y la corrección a enunciados imperativos y prescriptivos. En física, química o biología no podemos establecer normas de comportamiento, tampoco evaluar su desempeño, pues no pueden ser culpables o responsables, ni podemos pedirles que cambien sus normas o sus comportamientos; además, no se les puede aplicar un modelo de motivación como los que se muestran en la fase de dirección del proceso administrativo.

Sólo a los seres humanos se les puede hacer responsables del no cumplimiento de normas prescritas, del bien o mal desempeño, de las desviaciones y del requerimiento de una vigilancia en la ejecución de los planes. Los controles, en el sentido administrativo, sólo se pueden aplicar a los seres humanos, pues son criterios de desempeño fundados en planes. Lo que debe suceder se formula mediante enunciados prescriptivos que vienen desde la misión, objetivos, metas, hasta las estrategias que fueron los medios prescritos. Qué debe hacer un subordinado y la evaluación de preferencia con tinte emotivo, se construye con enunciados ilocucionarios. No son enunciados legaliformes del tipo leyes de la genética o de la mecánica clásica.

${ }^{33}$ Los enunciados evaluativos, críticos, valorativos y normativos son familiares a este concepto. 
La corrección de desviaciones se hace con enunciados prescriptivos como con enunciados exclamativos, donde se cuelan emociones y valores. Se pueden dar enunciados que son consejos, sugerencias, órdenes, amenazas ${ }^{34}$, promesas, insinuaciones, felicitaciones, entre otros. Que no son enunciados del tipo ley o hipótesis científica, que no son verificativos, sino que tienen relación con la acción de las personas.

Las técnicas y sistemas de control son esencialmente los mismos trátese de dinero, procedimiento de oficina, moral de los empleados, calidad del producto, o cualquier otra cosa que suceda en las organizaciones.

\section{Conclusión}

La parte importante del discurso administrativo no está constituido por enunciados verificativos o constatativos, sino realizativos o performativos; en especial éstos tienen la función de construir una organización lucrativa, humana o no (Aktouf, 2001). Pareciera que desde las palabras que forman su estructura, ésas no son palabras de corte científico según el canon positivista, no son palabras que refieran a hechos reales como la planeación, organización, integración, dirección y control. Ya sea como sustantivos o como verbos refieren al orden, performativo o realizativo, no al orden constatativo, hacen realidad social, patrones de acción productivos; algunos ejemplos de verbos serían: planear, organizar, integrar, dirigir y controlar; éstas son palabras que llevan a la acción como causa que pretenden un efecto, desde una intención, y no buscan la verdad, sino la efectividad.

De igual forma, los contenidos de cada una de estas partes de dicha estructura tienen un sesgo hacia la eficacia — dinero y poder — más que hacia la verdad; de ahí que tomen a los enunciados y palabras ilocucionarias que buscan más que la verdad, la eficacia. Palabras como misión, objetivo, planear, controlar, dirigir, integrar, sugerir, amenazar, prometer, sugerir, dirigir, motivar, comunicar, liderar,

\footnotetext{
${ }^{34}$ No hay que olvidar que las palabras hacen daño. Un caso: el mobbing, asediar, acosar, el acoso laboral, moral en el lugar de trabajo, con el objetivo de producir miedo o terror en el trabajador, ya sea para que cumpla sus tareas, para elevar su desempeño o para señalar errores que haya cometido el trabajador. En buena parte se habla de violencia psicológica injustificada. Cuando es recibida del jefe le llaman bossing. Dicha violencia psicológica se hace de forma sistemática y recurrente durante un tiempo prolongado. Palabras que insultan, que amenazan, promesas no cumplidas, palabras con ironía, con burla, no decirle nada, hablarle de manera diferente, palabras discriminatorias, estigmatizarlo ante los demás compañeros, difamarlo.
} 
así como enunciados prescriptivos, imperativos, normas, objetivos, exclamativos, serán el material fundamental del discurso administrativo, y sin el cual no se podría construir una realidad social como una empresa, además de los enunciados constatativos o científicos.

Aun los enunciados que pueden ser constatativos descriptivos son utilizados para lograr una acción; son empleados para lograr un efecto para mover a la acción o para hacer una organización.

Como ya lo señalan los Critical Management Studies, la forma realizativa de dichas palabras o proposiciones no son consensuadas ${ }^{35}$ (Habermas, 1987), sino aun en el intento de horizontalidad responden a un esquema vertical (Aktouf, 2001) ${ }^{36}$, impositivo, muchas veces manipulativo, donde los actos del habla imponen los intereses de una persona o grupo de personas. Habermas ya dejaba ver este problema en los actos del habla realizativos como forma de racionalidad instrumental. Bernard (1975) ya señalaba que la autoridad debe venir de "abajo"; los miembros deben decidir aceptar o no la autoridad de los superiores. Las teorías del liderazgo pueden mostrar las cosas que se pueden hacer con el habla.

Este sesgo realizativo más que constatativo de los actos del habla se puede encontrar en el discurso administrativo; cualquier autor habla de tal estructura administrativa, uno muy revisado es Koontz.

Searle (1997) llega a ver una función más de las palabras, su capacidad creativa ya sea por la parte normativa o por la parte significativa, así como por la parte de asignar funciones a las cosas y personas. Esto es, las palabras pueden crear realidad social, como las organizaciones productivas, generalmente injustas; por ello, debemos hacernos responsables de los actos del habla.

\footnotetext{
${ }^{35}$ Habermas (1989) y Apel (1975) proponen un modelo -desde la semiótica y la pragmática en particular- una acción comunicativa contra la acción estratégica, propone condiciones ideales del habla, basadas en una racionalidad dialógica, donde prive el mejor argumento. Habermas propone la norma: que frente a a un conflicto de intereses se busque la solución por medio de la argumentación y no de la violencia, las cuestiones de pretensión de validez se hará por argumentos y contraargumentos racionales, buscando la veracidad y rectitud, no la verdad. El criterio de solución es el consenso.

${ }^{36}$ Como señalaba antes, Aktouf muestra la importancia de ciertas palabras y frases, sus significados permiten construir organizaciones injustas, palabras como propiedad privada, maximización de ganancias, productividad, división social y técnica del trabajo, trabajador entendido como pasivo, hombre-masa, subordinación sistemática, palabras que hacen el trabajo inalienable.
} 


\section{Referencias}

Aktouf, O. (2001). La administración: entre tradición y renovación. Cali: Artes Gráficas del Valle.

Apel, K.O. (1975). El problema de la fundamentación última filosófica a la luz de una pragmática trascendental del lenguaje. México: Diánoia.

Austin, L. J. (1971). Cómo hacer cosas con palabras: palabras y acción. Madrid: Paidós.

Austin, L. J. y Searle (1991). Emisiones realizativas. En L. Valdés Villanueva (1991). La búsqueda del significado. Madrid: Tecnos.

(1991). ¿Qué es un acto del habla? En L. Valdés Villanueva (1991). La búsqueda del significado. Madrid: Tecnos.

Berger, L. P. y T. Luckmann (2008). La construcción social de la realidad. Buenos Aires: Amorrortu.

Bernard, C. (1975). Las funciones de los elementos dirigentes. En José, M. de Anzizu (compilador). Las funciones directivas. Barcelona: Labor.

Chavenato, I. (2007). Introducción a la teoría general de la administración. $7^{\mathrm{a}}$. ed., México: McGraw-Hill.

Cruz Soto, Luis Antonio (2010). El concepto de autoridad en el pensamiento de Aristóteles y su relación con el concepto de autoridad en el comportamiento administrativo. Contaduría y Administración, mayo-agosto (231): 53-78.

Fernández Arena J. A. (1969). El proceso administrativo. México: Herrero Hermanos.

Foucault, M. (1990). Tecnologías del yo y otros textos afines. Madrid: Paidós.

(2005b) (en español). Vigilar y castigar. El nacimiento de la prisión. Madrid: Siglo XXI. 
Galicia O., David (2009). El discurso administrativo y la tradición pragmática. Contaduría y Administración, septiembre-diciembre (229): 135-153.

González-Castán, Óscar (1992). Intencionalidad sin conciencia: Bretano, Searle y las ciencias cognitivas. Revista de Filosofía, $3^{\mathrm{a}}$ época, V (7).

Grice, H. P. (1968). Las intenciones y el significado del hablante. En L. Valdés Villanueva (1991). La búsqueda del significado. Madrid: Tecnos.

Habermas J. (1989). Teoría de la acción comunicativa I. Madrid. Taurus. (1998). Conciencia moral y acción comunicativa. $5^{a}$ ed., Barcelona: Península.

Kliksberg, Bernardo (1990). El pensamiento organizativo. De los dogmas a un nuevo paradigma gerencial. Prólogo de Jorge Etkin. Buenos Aires. Editorial Tesis.

Koontz, Harold y Weihrich Heinz(1998). Administración, una perspectiva global. $11^{\mathrm{a}}$ ed., México: McGraw-Hill.

(2001). Elementos de la administración. 6 ${ }^{\mathbf{a}}$ ed., México: McGrawHill.

Kuhn, Thomas S. (2007). La estructura de las revoluciones científicas. México: Fondo de Cultura Económica.

Lakatos, Imre (1983). La metodología de los programas de investigación. Madrid: Alianza Universidad.

Laudan, Larry (1977). Progress and Its Problems. Berkeley: University of California Press.

O. da Silva Reinaldo (2002). Teorías de la administración. México: Thomson.

Olivé Léon (2000). El bien, el mal y la razón. Facetas de la ciencia y de la tecnología. México: Paidós. 
Reyes Ponce, A. (1968). Administración de empresas. Teoría y práctica. México: Limusa.

Ríos Szalay, Jorge (1997). Mitos sobre el proceso administrativo: el modelo teórico- descriptivo vis a vis el modelo técnico-prescriptivo. Contaduría y Administración, abril-junio (185): 49-61.

Rorty Richard (1993). Heidegger, contingencia y pragmatismo. En Ensayos sobre Heidegger y otros pensadores contemporáneos. Escritos filosóficos 2. Trad. Jorge Vigil Rubio. Barcelona: Paidós.

Russell, Bertrand (1991). Los problemas de la filosofía. Barcelona: Labor.

(1973). Sobre el denotar. En T. Moro Simpson (comp.). Semántica filosófica: problemas y discusiones, Buenos Aires: Siglo XXI.

Searle, J. R. (1983). Intentionality: An Essay in the Philosophy of Mind. Cambridge: University Press.

(1997). La construcción de la realidad social. Barcelona: Paidós.

(1999): ¿Qué es un acto del habla? Revista Teorema XVIII (1).

Skinner, Quentin (1999). Algunos problemas en el análisis del pensamiento y la acción políticos. En A. Velasco (compilador). Resurgimiento de la teoría política en el siglo XX. México: UNAM.

Terry G. (1971). Principios de la administración. México: Continental.

Velasco, Ambrosio (1999). Resurgimiento de la teoría política en el siglo XX. Antología. México: UNAM.

Weber, Max (1999). Economía y sociedad. México: Fondo de Cultura Económica. 
